\title{
Cecal Intussusception in an Adult with Cronkhite-Canada Syndrome Relieved by Colonoscopy
}

\author{
Emi Ishikawa ${ }^{1}$, Masatoshi Kudo ${ }^{1}$, Yasunori Minami ${ }^{1}$, Kazuomi Ueshima ${ }^{1}$, \\ Satoshi Kitai ${ }^{1}$ and Kazuki Ueda ${ }^{2}$
}

\begin{abstract}
Cronkhite-Canada syndrome (CCS) is a rare, noninherited gastrointestinal polyposis syndrome associated with characteristic ectodermal abnormalities. Here, we report a case of Cronkhite-Canada syndrome with cecal intussusception relieved by colonoscopy. A 52-year-old man who was diagnosed as CCS pathologically two years previously presented abdominal pain and sub fever-up. Physical examination revealed the palpable mass sized approximate $10 \mathrm{~cm}$ in diameter in the upper abdominal site, in addition to the symptoms of alopecia, absent fingernails and toenails. However, abdominal wall rigidity and rebound tenderness were never expressed. Abdominal plain CT showed concentric circles from the ascending to the middle of the transverse colon, and a tumor in the lumen at the middle of the transverse colon. Colonoscopic reduction was performed first because we diagnosed it as intussusception due to CCS polyps without peritoneal irritation, and his symptoms were improved dramatically after careful reduction. Therefore, he was able to undergo the laparoscopic ascending colectomy as scheduled.
\end{abstract}

Key words: Cronkhite-Canada syndrome, intussusception, colonoscopic reduction

(Inter Med 49: 1123-1126, 2010)

(DOI: 10.2169/internalmedicine.49.2813)

\section{Introduction}

The patients with sigmoid volvulus or intussusception require an emergent surgery or colonoscopy to avoid a necrosis or perforation of digestive organs. The cause of intussusception in adulthood is often a tumor in the colon or small intestine (1). Therefore, some investigators have pointed out the risks of perforation and cancer cells seeding into the abdominal cavity in patients with advanced cancers caused by colonoscopic reduction (2-4). However, colonoscopic reduction may be able to reduce the necessity of an emergent surgery in intussusceptive patients with low malignant potentials and no peritoneal irritation sign.

Cronkhite-Canada syndrome (CCS) is a rare acquired gastrointestinal polyposis syndrome of unknown etiopathogenesis, accompanied by alopecia, custaneous hyper pigmentation, onychodystrophy, diarrhea, and dysgeusia (5). The syndrome is characterized by the presence of nonadenomatous inflammatory polyps that occur throughout the gastrointestinal tract, except for the esophagus (6-13). We report a case of Cronkhite-Canada syndrome presenting cecal intussusception relieved by colonoscopy.

\section{Case Report}

After several days of abdominal pain and low-grade fever, a 52-year-old man presented at our hospital. This patient had been seen regularly at our hospital during the past two years as an outpatient for follow-up of CCS. He had taken cox-2 inhibitor orally, but did not have a history of steroid use because of no phenomenon of protein-losing enteropathy and malnutrition. The present physical examination revealed a palpable mass approximately $10 \mathrm{~cm}$ in diameter in the upper abdomen, as well as symptoms of alopecia and missing finger and toenails. However, no abdominal wall rigidity or rebound tenderness was observed. Laboratory data indicated normal electrolytes and kidney and liver function. His he-

${ }^{1}$ Division of Gastroenterology and Hepatology, Department of Internal Medicine, Kinki University School of Medicine, Osaka-Sayama and ${ }^{2}$ Department of Surgery, Kinki University School of Medicine, Osaka-Sayama

Received for publication August 24, 2009; Accepted for publication January 21, 2010

Correspondence to Dr. Masatoshi Kudo, minkun@med.kindai.ac.jp 


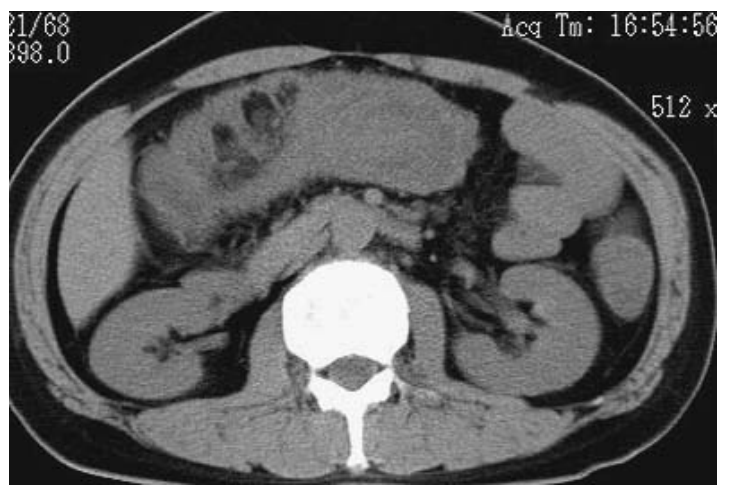

Figure 1. Abdominal plain CT showing a pattern of concentric circles from the ascending colon to the middle of the transverse colon.

moglobin was $12.9 \mathrm{~g} / \mathrm{dL}$, white blood cell count was 4,100/ $\mathrm{mm}^{3}$, CRP $0.063 \mathrm{mg} / \mathrm{dL}$. Serum proteins were $6.4 \mathrm{~g} / \mathrm{dL}$ and albumin was $3.7 \mathrm{~g} / \mathrm{dL}$. Serum CEA and CA19-9 were 1.1 $\mathrm{ng} / \mathrm{mL}$ and $10 \mathrm{IU} / \mathrm{mL}$, respectively. Plain abdominal CT showed a pattern of concentric circles from the ascending colon to the middle of the transverse colon, where a tumor was lodged in the lumen (Fig. 1). There were no signs of severe ischemia or necrosis at the base and the head of the intussusception.

Based on our diagnosis of intussusception due to CCS polyps, but with no peritoneal irritation, we performed colonoscopic reduction with the support of a surgeon. Colonoscopy revealed a focus of redness in the middle of transverse colon that centered on a large polyp with an irregular surface (Fig. 2a). Fluorography with meglumine sodium amidotrizoate during colonoscopy showed an obstruction that did not fill the proximal transverse colon (Fig. 2b). We took care that the scope was not pushed against consistent rigidity, and used the handling of air insufflation efficiently. Therefore, with careful handling of the colonoscope, we confirmed that the intussusceptions were relieved (Fig. 3a). Images also revealed a large and irregular polyp in the cecum (Fig. 3b), and small polyps in the colon.

The patient improved dramatically after intussusception reduction, however he underwent laparoscopic ascending colectomy as scheduled due to relapses. The main polyp in the cecum was grounded with a thick stalk that had an irregular, granulated surface. Dilative cystic ductal structures and a severe infiltration of inflammatory cells were confirmed pathologically for this polyp, but no colon cancer cells were detected. Thereafter, the patient showed no postoperative symptoms and remained in good condition for one year after surgical operation.

\section{Discussion}

CCS is characterized by the presence of diffuse gastrointestinal (GI) polyposis, dystrophic changes in the fingernails, alopecia, cutaneous hyperpigmentation, diarrhea, weight loss, abdominal pain, and other GI complications such as
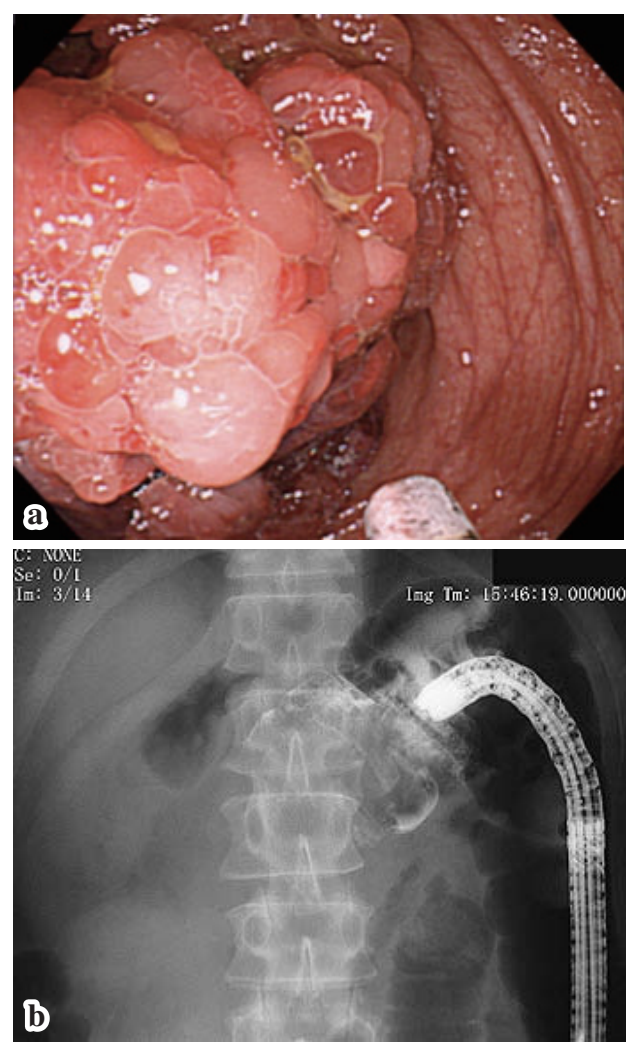

Figure 2. Colonoscopic appearance of broad-based hamartomas typical of CCS in the middle of transverse colon (a). Fluorography with meglumine sodium amidotrizoate showed an obstruction and the subsequent extended colon (b).

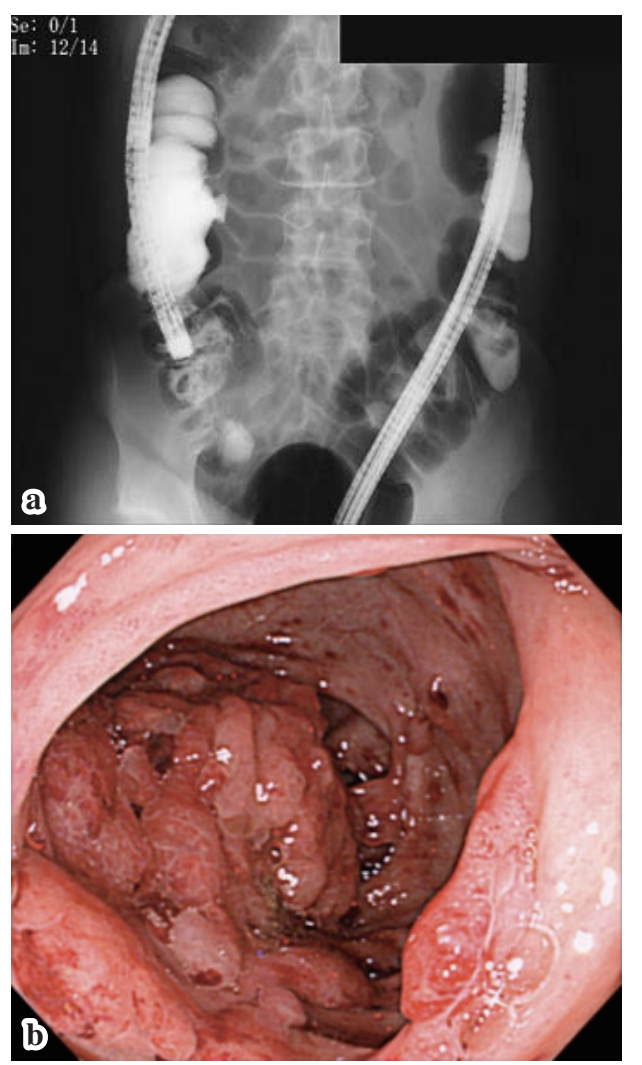

Figure 3. Images of fluorography with meglumine sodium amidotrizoate (a) and colonoscopy (b) were obtained after the reduction of intussusception. 
protein-losing enteropathy and malnutrition (5-13). Malignant transformation of polyps is considered to be infrequent, however, there were 50 cases of CCS associated with gastrointestinal cancer reported up to 2002, including 31 cases of colon cancer and 19 cases of gastric cancer $(12,13)$. Therefore, surveillant upper and lower endoscopy should be performed regularly.

Intussusception itself in adults occurs relatively rarely; however, a specific lead point is identified in more than $90 \%$ of cases $(14,15)$. A correct and timely diagnosis is not only necessary to avoid the complications of bowel infarction and perforation secondary to high-grade obstruction but also to resect the underlying lesion that serves as a lead point. Therefore, knowledge of the imaging spectrum and the clinical features of intussusception are important because imaging plays a crucial role in the diagnosis and management of these patients. Typical intussusception is well diagnosed on CT, which shows a pathognomonic bowel-withinbowel configuration $(15,16)$, appears as a sausage-shaped mass when CT images is obtained parallel to its longitudinal axis of digestive tract but as a target-like mass when CT images is perpendicular to the cross sections of digestive tract $(15,16)$. Sonography can facilitate the diagnostic decision when the characteristic sign of a target like lesion or bull's eye lesion is shown, similar to the CT findings (15). We could diagnose the intussusception in this patient immediately by these typical findings of imaging.

Intussusceptions associated with CCS have been reported as a case report in at least four patients in Japanese language up to 2007 (17-19) in spite of no report in the English language literature. According to these literatures, intussusceptions had occurred at the ascending colon/cecum. This patient underwent laparoscopy as a therapeutic procedure, and improved. No 30-day mortality was encountered in this review. Intraoperative reduction before resection was attempted in only one patient. It was successful; nevertheless, the surgical treatment was required because of a relapse of intussusceptions.

There has been controversy associated with the option of preliminary reduction of the intussusception before resection vs. primary resection without reduction (1). The theoretic objections to reduction of grossly viable bowel with mucosal necrosis are: 1) intraluminal seeding and venous embolization of malignant cells in the region of ulcerated mu- cosa, 2) possible perforation during manipulation, 3) increased risk of anastomotic complications in the face of edematous and inflamed bowel (2-4). Reduction should not be attempted if there are signs of bowel ischemia or inflammation. Based on a high incidence of an underlying malignancy, which may be difficult to confirm intraoperatively, many authors recommend primary resection whenever possible. However, emergency operation was generally associated with high rates of complications and mortality (20). In patients with early stage of intussusceptions without peritoneal irritation, careful colonoscopic reduction would have less risk of tumor cell seeding, perforation, and anatomic complications; therefore, colonoscopic reduction ought to be attempted in cooperation with surgeons for the avoidance of emergency surgery.

Several reports have discussed intussusceptions associated with Peutz-Jeghers syndrome, a kind of disease of multiple polyposis (21-23). Peutz-Jeghers syndrome is characterized by hamartomas throughout the gastrointestinal tract, mucocutaneous melanotic spots and increased predisposition to malignancy. The polyp stalk of Peutz-Jeghers syndrome tends to lengthen with the growing of polyps. The bigger polyp with long stalk as the lead point of an intussusception may be outlined distal to the tapered lumen of the intussusceptum. On the other hand, polyps of CCS tend to be relatively small without a long stalk. However, in these patients, the larger size of the cecum polyp might be occur in spite of the thick stalk of the polyp. Not only polyposis but also inflammatory bowel disease could cause giant pseudopolyps. Colonic intussusception of a giant pseudopolyp was reported in a patient with inflammatory bowel disease $(24,25)$.

In conclusion, we described an adult with cecal intussusception due to CCS polyps that was relieved by colonoscopy. Colonoscopic reduction may reduce the necessity of an emergent surgery in intussusceptive patients with low malignant potential and no peritoneal irritation sign.

\section{Author contributions:}

Guarantors of integrity of entire study, E.I., M.K.; study concepts and design, E.I; definition of intellrctual content, E.I, S.H, M.Y; literature research, U.K, H.S; clinical study, E.I, U.K; data acquisition and analysis, E.I, H.S; manuscript preparation, E.I; manuscript editing and review, E.I, M.Y, K.M

\section{References}

1. Zubaidi A, Faisal AS, Silverman R. Adult intussusception: a retrospective review. Dis Colon Rectum 49: 1546-1551, 2006.

2. Weibaecher D, Bolin JA, Hearn D, et al. Intussception in adults. Review of 160 cases. Am J Surg 121: 531-535, 1971.

3. Reijnen HA, Joosten HJ, de Boer HH. Diagnosis and treatment of adult intussception. Radiology 124: 791-792, 1977.

4. Eisen LK, Cunningham JD, Aufses AH Jr. Intussception in adults: institutional review. J Am Coll Surg 188: 390-395, 1999.

5. Cronkhite LW Jr, Canada WJ. Generalized gastrointestinal polyposis: An unusual syndrome of polyposis, pigmentation, alopecia and onychotrophia. N Engl J Med 252: 1011-1015, 1955.

6. Ward EM, Wolfsen HC. Review article: The non-inherited gastrointestinal polyposis syndromes. Aliment Pharmacol Ther 16: 333$342,2002$.

7. Takakura M, Adachi H, Tsuchihashi N, et al. A case of CronkhiteCanada syndrome markedly improved with mesalazine therapy. Dig Endosc 16: 74-78, 2004.

8. Kubo T, Hirose S, Aoki S, et al. Canada-Cronkhite syndrome associated with systemic lupus erythematosus. Arch Intern Med 146: 995-996, 1986. 
9. Murata L, Yoshikawa L, Endo M, et al. Cronkhite-Canada syndrome: report of two cases. J Gastroenterol 35: 706-711, 2000.

10. Takeuchi Y, Yoshikawa M, Tsukamoto N, et al. Cronkhite-Canada syndrome with colon cancer, portal thrombosis, high titer of antinuclear antibodies, and membranous glomerulonephritis. J Gastroenterol 38: 791-795, 2003.

11. Goto A, Shimokawa K. Cronkhite-Canada syndrome associated with lesions predisposing to development of carcinoma. Cancer Ther 29: 1767-1777, 1994.

12. Negoro K, Takahashi S, Kinouchi $Y$, et al. Analysis of the PTEN gene mutation in polyposis syndromes and sporadic gastrointestinal tumors in Japanese patients. Dis Colon Rectum 43: S29-S33, 2000.

13. Yashiro M, Kobayashi H, Kubo N, Nishiguchi Y, Wakasa K, Hirakawa K. Cronkhite-Canada syndrome containing colon cancer and serrated adenoma lesions. Digestion 69: 57-62, 2004.

14. Agha FP. Intussusception in adults. AJR 146: 527-531, 1986.

15. Choi $\mathrm{AH}$, Han JK, Kim $\mathrm{AH}$, et al. Intussusception in adults: from stomach to rectum. AJR 183: 691-698, 2004.

16. Floemer F, Bissig H, Oertli D, et al. Multislice CT in adult colocolic intussusception: case report and review of the literature. Emerg Radiol 15: 361-366, 2008.

17. Futagami Y, Tanaka S, Haruma K, et al. A case of CronkhiteCanada syndrome complicated with colonic invagination. Gastroenterological endoscopy 39: 1602-1607, 1997.
18. Yamamoto T, Tanaka Y, Motizuki S, et al. A case report of intussusception due to the polyp of Cronkhite-Canada syndrome. Jap J Gastroenterol Surg 40: 1250, 2007.

19. Morinaga N. Two cases report of intussusception with CronkhiteCanada syndrome. J Abd Emerg Med 14: 243, 1995.

20. Kim J, Mittal R, Konyalian V, et al. Outcome analysis of patients undergoing colorectal resection for emergent and elective indication. Am Surg 73: 991-993, 2007.

21. Talwar N, Mohan S, Andley M, et al. Prograde and retrograde intussusception: A rarity in Peutz-Jeghers syndrome. Int Surg 91: 265-266, 2006.

22. Akimaru K, Katoh S, Ishiguro S, et al. Resection of over 290 polyps during emergency surgery for four intussusceptions with Peutz-Jeghers syndrome: Report of a case. Surg Today 36: 9971002, 2006.

23. Jaremko JL, Rawat B. Colo-colonic intussusception caused by a solitary Peutz-Jeghers polyp. Br J Radiol 78: 1047-1049, 2005.

24. Atten MJ, Attar BM, Mahkri MA, Del Pino A, Orsay CP. Giant pseudopolyps presenting as colocolic intussusception in Crohn's colitis. Am J Gastroenterol 93: 1591-1592, 1998.

25. Maldonado TS, Firoozi B, Stone D, Hiotis K. Colocolonic intussusception of a giant pseudopolyp in a patient with ulcerative colitis: a case report and review of the literature. Inflamm Bowel Dis 10: 41-44, 2004.

(C) 2010 The Japanese Society of Internal Medicine

http://www.naika.or.jp/imindex.html 